\title{
Colombia: de la crisis política a la democracia participativa
}

\author{
Diego Jaramillo Salgado \\ Universidad del Cauca, Popayán, Colombia
}

\section{Introducción}

El proceso político colombiano adquiere hoy singular importancia para el pueblo latinoamericano y para las ciencias sociales por los bruscos y vertiginosos cambios producidos en menos de una década. Primero fue la negociación con grupos guerrilleros que llevó a la desmovilización de varios de ellos y la incorporación de sus militantes a la vida civil. Luego, la fuerte confrontación del Estado al narcoterrorismo y al narcotráfico que no sólo acabó con algunos de sus capos y puso en la cárcel a otros sino que, contradictoriamente, develó su presencia en las redes mismas del poder gubernamental en el reciente enjuiciamiento al presidente Samper. Por último, el proceso que condujo a la elección de los miembros de la Asamblea Nacional Constituyente y el significado que tiene la nueva constitución; aunque haya en la actualidad intentos de contrarreforma.

Sin embargo, estos hechos no pueden tomarse en sí mismos, aislados de los elementos propios de su conformación. Es por esto que intentamos hacer un análisis del proceso político colombiano en las tres últimas décadas, teniendo en cuenta los fraccionamientos que se fueron produciendo en el Estado, los partidos y las instituciones. Se enfatizan aquellos aspectos que inciden en la formación de una cultura política de la intolerancia; no sólo desde las instancias que provienen directamente del aparato estatal, sino también de las formas de hegemonía que lo atraviesan y de las prácticas que pretenden estructurarse desde la resistencia, postulándose corno alternativas políticas a las dominantes. Por ello los ejes de análisis son: el papel del Frente Nacional en la pérdida de legitimidad del Estado, el proceso de ascenso y crisis de las izquierdas, y las prácticas que se adelantan para garantizar la paz. De tal manera que, a través de ellos, se pueden identificar los elementos que indujeron a la ausencia del Estado, corno algunos analistas lo argumentan, atizaron la crisis política, y, a su vez, aquéllos que se definieron en función de darle una reorientación política al país. 


\section{El Frente Nacional y la Política de la Intolerancia ${ }^{1}$}

Cuando los dirigentes de los dos partidos tradicionales, el liberal y el conservador, hicieron el pacto que produjo el frente nacional no intuyeron las secuelas que podría derivar. En efecto, su propósito fue el de crear mecanismos de convivencia que erradicaran la incontrolable violencia que se vivía. Mucho más cuando eran conocedores de que las causas de los conflictos tenían corno una de sus explicaciones la rivalidad que entre ellos se había precipitado en la década del 40.

Efectuado el acuerdo se atenuaron los conflictos que inducían a la violencia. El país entró por un sendero de modernización relativa, corno pocas veces en su historia, y agilizó su proceso de urbanización colocándose corno uno de los países con más centros urbanos en América Latina. Esto no significa que a la par se hubiera conformado una cultura citadina, pero sí una tendencia a su estructuración como tal.

Las reglas de juego establecidas por el Frente Nacional pretendían que la sociedad civil entrara a disfrutar de los logros de la modernidad a través de una confrontación política "civilizada”. Se propugnaba por que la lucha de los partidos, sus ideologías y la de los líderes o de los caudillos fuera encauzada hacia una convivencia que propiciara la normalidad. Para ello efectuaron una reforma de la constitución (Plebiscito de 1957) en la que se consagraron así mismas como los únicos partidos aceptables dentro de la legalidad colombiana. Obviaron la disputa del poder aceptando una alternación en cada periodo presidencial, hasta 1974. Atenuaron las intrigas que se presentaban en la repartición de la burocracia, distribuyéndose "equitativamente" los puestos públicos. Se aseguraron de que sólo ellos pudieran producir nuevas reformas a la carta magna, aceptando que sólo se hiciera a través del congreso.

Así, lo que en sus primeros años fueron los instrumentos de reconciliación nacional se convirtieron con el tiempo en la legitimación de la más crasa cultura de la intolerancia. Los dos partidos fueron perdiendo elementos que los diferenciaran. No se podía hablar ni de conservatismo ni de liberalismo como proyectos políticos o ideológicos; incluso ni como partidos. No se podía hablar de fronteras. Quizá predominaba una forma de conservatización, como se verá más adelante. Por tanto no se podía pensar en que hubiera oposición entre ellos mas allá de las prioridades que se establecían en tomo de las cuotas burocráticas.

1 Hay una amplia bibliografía sobre el Frente Nacional; sin embargo, en relación con el sentido que aquí se le quiere dar se puede consultar: Ricardo Santamaría y Gabriel Silva Luján. Proceso político en Colombia Del Frente Nacional a la apertura Democrática, CEREC, Bogotá, 1986. 
El Congreso mismo perdía su razón de ser. No era el organismo que representara los intereses populares o nacionales. Tampoco el agente legislativo que regulara la vida nacional. Se convirtió más bien en el instrumento de intereses de partidos, de grupos o de personas. Se instituyeron los "auxilios parlamentarios" por medio de los cuales cada congresista aseguraba una porción de la clientela en cada región. Fue así como la antesala de cada elección era el despliegue de ofertas para la realización de obras que quedaban a medio camino, y su continuación o término se postergaba para un próximo proceso electoral. Se repartían becas por medio de las cuales se aseguraba el voto del beneficiado o de su familia. Cuando nada de esto servía se disponía de cierta cantidad de dinero, que se aumentaba dependiendo de las relaciones que se tuvieran con la mafia, para comprar directamente votos o pagarlos en especie: un almuerzo, camisetas, transporte, etc. Se oficializaron, los viajes al exterior que el lenguaje común identificó como "turismo parlamentario". Los miembros del Congreso eran nombrados en puestos claves de la administración pública, sin que perdieran su investidura parlamentaria. El presupuesto Nacional era elaborado y ejecutado teniendo en cuenta los requerimientos de los jefes políticos regionales y nacionales.

De allí que se fuera favoreciendo el fortalecimiento del ejecutivo, legalizado de una manera radical en la reforma constitucional de 1968. De esta forma la mayoría de los proyectos de ley no provenían de los parlamentarios sino de la iniciativa presidencial. Lo poco que había de planeación era asumido por el ejecutivo, al igual que la iniciativa del presupuesto y del gasto público. El orden público, a su vez, se centralizaba en él, por medio del permanente estado de sitio; de tal manera que no había ninguna fiscalización del Congreso y difícilmente de la Procuraduría General de la nación; lo cual propició un incremento de los hechos de violación de los derechos humanos. ${ }^{2}$

Los partidos dejaron de ser los mediadores entre la sociedad y el Estado para convertirse en simples agencias de empleo. No eran orientadores de la opinión pública respecto de los grandes problemas nacionales. No eran productores y formadores de ideología. La misma identidad orgánica se fue perdiendo con la multiplicidad de jefes regionales, que constituían especies de

Bastaría con analizar los informes anuales de Amnistía Internacional desde el gobierno de Julio César Turbay Ayala, de los comités de Derechos Humanos del país y de otros organismos internacionales para tener una idea de la magnitud del problema. De todas maneras, es significativo que desde el gobierno de Belisario Betancur se reconozca como política estatal la búsqueda de garantizar su defensa hasta el punto de haber creado, de manera permanente, una Conserjería Presidencial para la defensa y promoción de los Derechos Humanos. 
mini partidos. Los dineros con los cuales se sostenían, no tenían ningún tipo de control, propiciando la injerencia del narcotráfico en la constitución de sus fondos.

El Frente Nacional se consolidó a la par que el ascenso del militarismo y del autoritarismo de Estado, cuyo acicate fue el triunfo de la Revolución $\mathrm{Cu}$ bana y la agudización del conflicto Este-Oeste, que generalizaron en América Latina la Doctrina de la Seguridad nacional y que tendrían en Colombia un significado especial. Principalmente porque se había experimentado un régimen militar (1953-1957) que culminó con una dictadura, con las secuelas que esto produjo en la cultura política y porque aún se vivía una violencia generalizada que invadía los mínimos espacios posibles para la cotidianidad.

En efecto, una de las concesiones que se hizo a los militares fue mantener como ministro de defensa (de guerra, en ese entonces) a un militar. ${ }^{3}$ Quizá la mayor fue mantener al país en estado de sitio permanente. Los diferentes gobiernos cedieron porcentajes del presupuesto nacional al aparato militar en detrimento de la educación, la salud y de la mayoría de programas de beneficio social. La concepción militar, y muchas de sus prácticas, se afianzaron con la creación de universidad, escuelas y colegios militares; con su inclusión, casi obligada, en la mayoría de acontecimientos de la vida nacional de carácter oficial, y, en no pocas veces, privada.

El ministro de defensa del gobierno de Turbay Ayala defendía la tesis de que la existencia de un vacío de poder, por la crisis de los partidos y la descomposición de las instituciones, debía ser cubierto por las fuerzas militares. El presidente compartía esta postura. Belisario Betancur frenó el envalentonamiento de su primer ministro de defensa, quien se oponía a su política de paz, haciéndolo renunciar. Pero luego cedió ante el aparato militar, en lo que se ha calificado como un "minigolpe de estado", en la acción de arrasamiento bélico de que fueron objeto los miembros de la Corte Suprema de Justicia, empleados, ciudadanos y guerrilleros en el conocido hecho del Palacio de Justicia. ${ }^{4}$

En consecuencia, todo movimiento cívico, toda reivindicación gremial era calificada como subversiva y sujeta por lo tanto a la reacción militar. Los mínimos márgenes de protesta aceptados legalmente, eran violados o relega-

3 Véase Gustavo Gallón Giraldo. La República de las armas. Bogotá, CINEP, Controversia, Números 109-110, 1983.

4 Quizá la mejor investigación que se ha realizado sobre este hecho sea la de Humberto Velez Ramírez y Adolfo L Atehortúa Cruz, editada con el titulo Militares, guerrilleros y autoridad civil. El caso del Palacio de Justicia, Universidades del Valle y Javeriana, Cali, 1993. 
dos por los gobiernos y los militares, a través del estado de sitio, que era justificado por la existencia de una "conmoción interior". Era imposible por lo tanto el avance de cualquier alternativa de poder o de simples intentos de oposición.

Los medios de comunicación, cuyo papel preponderante en la formación de opinión pública y, en general, de cultura política hoy no lo discute nadie, se modernizaron al vaivén de los juegos de fuerza que se vienen analizando. Por tanto, les era congruente la descalificación de la oposición, el privilegio a los monopolios económicos, el favorecimiento a los partidos políticos tradicionales, el control de la información por parte de los militares. De hecho, la distribución de los espacios informativos y de opinión se hacía en función de las cuotas de poder que predominaban en la vida política nacional. La presentación y representación de los acontecimientos nacionales y mundiales eran manipulados por los dominadores de turno. El imaginario social dominante era aquél que se estructuraba desde las ventajas que arrojaba el poder político.

La educación no fue ajena a este proceso de centralización y de manipulación desde los ejes de poder. La principal tendencia fue el abandono por parte del Estado de las funciones y atribuciones que la constitución le señalaba. Esto hizo que se fortaleciera la educación privada, con el previsible deterioro de la educación pública. Los centros educativos también fueron pasto del clientelismo, frenado solamente por el avance de la lucha sindical del magisterio. Las políticas educativas, fluctuaban al vaivén de los funcionarios directivos de turno. Nada había más ajeno a las necesidades del país que las prácticas educativas.

Se destacan estos aspectos como las tendencias fundamentales del Frente Nacional, no quiere decir esto que sean los únicos en el fortalecimiento de una cultura de la intolerancia. Habría que señalar el tratamiento dado a los grupos étnicos minoritarios, a los grupos sociales concentrados en los espacios de mayor pobreza de las principales ciudades, a las demandas de los campesinos por tierra y de los destechados por vivienda. Es decir, el desconocimiento del otro, su exclusión, se convirtió en una práctica permanente que permeó, inevitablemente, las redes vitales de la cotidianidad. La Democracia, por tanto, sólo se mantenía en lo formal. Al mundo se le mantuvo la imagen de la existencia de un Estado de Derecho que sólo se reducía a la realización de procesos electorales. Pero, no se cuestionó si el proceso en sí mismo era democrático ni si se practicaban en el país todos los demás pilares de la Democracia. El ideal de una cultura democrática se opuso a la vivencia real del pueblo colombiano. 


\section{Ascenso y Crisis de Opciones Políticas de Izquierda}

Si se analiza la historia política de Colombia, se puede encontrar un arraigo en el imaginario social de que alternativas políticas, diferentes de las hegemónicamente dominantes, sólo pueden abrirse un espacio político por la vía de la violencia. Bastaría detenerse en las sucesivas guerras civiles de finales del siglo pasado, el plan insurreccional adelantado por el Partido Socialista Revolucionario, al terminar la década del 20, su contemporánea huelga bananera que en 1928 terminó con una masacre, y la denominada guerra civil que se precipitó en 1948. Pareciera que existiera una tendencia por medio de la cual las clases, élites y grupos hegemónicamente dominantes sólo pueden garantizar su legitimidad por medio del autoritarismo, y que, en consecuencia, las opciones alternativas sólo pudieran consolidarse con prácticas recíprocas.

Habría que escrutar también en la historia política y cultural de Colombia, las características particulares del intento de constitución de una Nación y las prácticas políticas institucionales y culturales que fueron consolidando los mecanismos de exclusión. Es allí en donde se podría relativizar la tesis de que le es connatural al pueblo colombiano ser violento. Y es allí en donde se pueden explicar las condiciones objetivas que motivan la presencia de organizaciones de izquierda. Especialmente en la concentración de la riqueza y la propiedad en pocas manos, con el consiguiente incremento de la pobreza, en la ausencia de espacios democráticos que le permitan al ciudadano y a sus organizaciones populares ejercer poder, y en el predominio de una cultura política que imposibilita procesos de negociación de los conflictos. Por supuesto, también se deben tener en cuenta las experiencias externas que permitieron consolidar el socialismo y que atizaron la confrontación Este-Oeste.

Sin embargo, la asimilación de estas experiencias sólo fue posible por las circunstancias y condiciones internas en que se desenvolvió la vida política, económica y social de la sociedad colombiana. Por ello, son varias las alternativas políticas que lograron tomar fuerza y que incidieron en el desarrollo institucional y cultural del país en las tres últimas décadas; pero que, sin embargo, coincidieron en muchos aspectos en su comportamiento político. Quiere decir esto que más acá de sus idearios políticos, funcionó una práctica diferenciada sólo por las siglas y emblemas de sus organizaciones y por el aislamiento a que los condujo su dogmatismo.

\section{El Partido Comunista, la Unión Patriótica y Las F ARC}

Se debe tener en cuenta, de manera prioritaria, al Partido Comunista Colombiano, por su significativa trayectoria en la historia política nacional 
desde 1930 y por la característica de estar respaldado, desde la década del 60, por un grupo armado: las Fuerzas Armadas Revolucionarias de Colombia (FARC). ${ }^{5}$ Hecho que posibilitó la adopción de la tesis de la combinación de las formas de lucha, que predomina en la actualidad. Con ella se justifica la acción legal del Partido dentro del trabajo de masas y se acepta la clandestinidad, ilegalidad y acciones violentas de la organización guerrillera.

Es posible que, en mucho, en esto se encuentre su debilidad en cuanto a la legitimidad social. Desde el punto de vista legal ha sido poco su avance en más de sesenta años de existencia. Sus continuos vaivenes en las alianzas electorales, su ambigüedad en el apoyo o enfrentamiento a gobiernos o políticas gubernamentales, acompañado de su dogmatismo y ortodoxia, y en no pocas veces de triunfalismo y sobrevaloración de sus fuerzas han hecho que su votación no haya pasado de un $6 \%$, y que cuando lo ha logrado sea contabilizando las alianzas con otros sectores; entre ellos, de los tradicionales.

Igualmente, el respaldo social que tienen las F ARC se ha reducido a las regiones campesinas en las cuales ejercen sus operaciones. Han consolidado su acción en donde no hay presencia del Estado, y en donde, en la práctica, el Estado es esa organización. Controlan el hurto, el robo, el asalto. Orientan sobre el tipo de productos que se requiere producir. Por ello no son pocas las zonas en las cuales grandes cultivos de coca son protegidos por la vigilancia y control de la guerrilla. Imponen a los propietarios de tierras y de ganado un impuesto (denominado por ellos "vacunas"). A la vez ejercen el secuestro y el asalto de bancos para garantizar su financiación económica. El dominio del territorio implica que no sólo el Estado no está presente o es desplazado sino que también cualquier organización guerrillera, gremial o política debe desaparecer de su zona de influencia.

Han tenido su incidencia en muchas de las movilizaciones campesinas y cívicas que se han efectuado en las dos últimas décadas en las regiones campesinas; sin embargo no se puede concluir de ello una lealtad a sus planteamientos y su organización. Más bien se puede pensar que la heterogeneidad de esas movilizaciones han fortalecido movimientos sociales que van más allá de los intereses de clase que ellos pregonan y que virtualmente han difuminado el apoyo popular que pudo darse en otro período. ${ }^{6}$

5 La forma como surgió esta organización guerrillera y sus acercamientos y distancias con el PCC son tratados en el libro de Eduardo Pizarro Leóngomez, Las FARC (1949-1966) De la autodefensa la combinación de todas las formas de lucha, Instituto de Estudios Políticos y relaciones Internacionales, Universidad Nacional y Tercer Mundo Editores, Santafé de Bogotá, 1991.

6 Véase Medófilo Medina, "La crisis de la izquierda en Colombia” en Revista Foro No. 15, 
No se puede evitar tener en cuenta que el papel asumido por el PCC en su larga historia ha hecho que se constituya en parte de la cultura política nacional. Mantiene desde hace muchos años un periódico semanal y revistas tanto en el grupo guerrillero como en la organización legal. Muchos de sus cuadros políticos han sido adalides de movimientos culturales, como la Corporación Nacional de Teatro. Sus congresistas, aunque en reducido número, son referente inevitable en las negociaciones políticas. Durante un largo tiempo, mantuvo el control de la Confederación Sindical de Trabajadores de Colombia (CSTC), y, a través de ella, impulsó la unidad con otras organizaciones para constituir la actual Central Única de Trabajadores (CUT). Insiste en que el partido debe ser de corte Marxista-Leninista y que se debe propiciar la alianza de la clase Obrero-Campesina. Pero, la cotidianidad política lo enfrenta a la defensa de los Derechos Humanos, la lucha contra el alto costo de vida, la defensa de los derechos laborales etc.

Si hubo momentos en los cuales la historia nacional parecía encontrar una alternativa en el Partido Comunista, no se puede decir lo mismo de lo que se expresa en este ocaso del siglo. Su acción política se coloca de espaldas a los grandes anhelos nacionales. Su maquinaria burocrática parece petrificada en el museo de los viejos recuerdos. Su capacidad organizativa parece debilitarse aún más, tanto en la vieja militancia como en las expectativas de apoyo popular.

Lo mismo se puede afirmar de la organización guerrillera. Aunque, se puede agregar a lo ya expuesto que, en gran parte, su mantenimiento se debe a que para muchos de sus militantes ya es una forma de vida: nacieron y se formaron en la guerrilla; trabajan la tierra amparados por la guerrilla o en función de ella. Además, la disciplina militar no es deliberativa y por lo tanto se obedecen las decisiones que los jefes han tomado, que el comando ha impuesto o el partido ha trazado. Esto hace que sea difícil pensar en que se puedan dar cambios en corto tiempo. Mucho más cuando la generalización de los atentados terroristas en alianza, no pocas veces, con el Ejército de Liberación Nacional desde 1990, ha inducido a sobrevalorar su fuerza y a considerar que está en capacidad de imponerle al gobierno nacional condiciones de negociación y logros considerables.

\section{El Ejército de Liberación Nacional}

El Ejército de Liberación Nacional, surgió al calor del triunfo de la revolución cubana. Se organizó siguiendo sus directrices, como tantas otras en

Santafé de Bogotá, septiembre de 1991, p: 45-52, y Gilberto Naranjo, "Movimiento guerrillero y tregua” en Movimientos sociales ante la crisis en Sudamérica, CINEP, Bogotá, 1986, p: 43-80 
Latinoamérica; con una orientación netamente foquista. El protagonismo más importante lo tuvo con la vinculación del sacerdote Camilo Torres Restrepo, en una extraña mezcla de sacralización y satanismo. Su composición social, en un comienzo, fue predominantemente estudiantil e intelectual; luego se amplió con militantes de origen obrero y campesino. Después de una crisis que casi lo hace desaparecer, resurgió de nuevo en la década pasada enarbolando como bandera principal la defensa de .las riquezas naturales, en especial el petróleo. Compartiendo con las FARC su predominio campesino y su control de zonas agrarias, mantuvo, durante varios años, su protagonismo con acciones terroristas. Su radical postura de no hacer política legal parece que fue rota a fines de la década pasada con la creación de la organización A LUCHAR, que efectuó su acción tanto en el campo como en la ciudad, y se diluyó hace pocos años.

Su lucha por el socialismo se mantiene coherentemente con el trabajo desarrollado en el centro petrolífero de Barrancabermeja, algunos sindicatos obreros de pocas ciudades y su confrontación actual a los monopolios del petróleo; sin embargo, su acción principal se ha desenvuelto en las regiones campesinas y su composición sigue siendo predominantemente campesina y de sectores medios de la población. Al igual que las FARC, se financian con el secuestro, los impuestos en las zonas que dominan, negociaciones con las transnacionales del petróleo, el asalto a bancos y el pago que reciben por la protección de zonas de cultivo de coca.

Ha intentado una unidad guerrillera a través de la Coordinadora Nacional Guerrillera Simón Bolívar, que se fundó estando el M-19 en armas; sin embargo, no son muy claras sus relaciones con esa organización ni tampoco su interés en mantenerse en ella, como sí lo fue en el periodo de negociaciones de las otras organizaciones guerrilleras que se reincorporaron a la guerra civil. De hecho, las conversaciones más recientes con el gobierno las adelantaron por su cuenta, lo mismo que algunas iniciativas tendientes a negociar la aplicación del Derecho Internacional Humanitario en la balbuceante búsqueda de adelantar un proceso de paz que los lleve a su desmovilización. Intención que no es muy clara puesto que se han radicalizado en sus acciones terroristas y continúan desarrollando su trabajo político en función de la acción violenta.

\section{M-19 y Alianza Democrática M-19 (Ad-M-19)}

El M-19 surgió del proyecto populista ANAPO (Alianza Nacional Popular), liderado por el general retirado Gustavo Rojas Pinilla, quien había sido presidente de la república a través de un golpe de estado. Su ilegalidad y clan- 
destinidad se dio por reacción al fraude electoral de 1970 en el cual habría triunfado el General Rojas. Ratificando con ello que el Estado colombiano no garantizaba espacios democráticos para el ejercicio de la política. Consideraba que la oligarquía concentraba tanto poder político como económico; a la vez, confrontaba la pérdida de la soberanía del país frente a las multinacionales de Estados Unidos. Retornaba el ideal de la unidad latinoamericana propugnado por Bolívar.

Su acción guerrillera combinaba actuaciones efectistas y populistas, al estilo de los Tupamaros del Uruguay, con la acumulación de fuerzas en sus frentes militares. Desde el robo de la espada de Bolívar para enfatizar su propósito latinoamericanista, pasando por la incautación de carros de alimentos que eran distribuidos en la población, y la toma de la embajada de la República Dominicana, hasta el asalto al Palacio de Justicia, en 1986.

Las simpatías que despertaban producían oscilaciones que difícilmente permitían identificar el grado de aceptación de que era objeto. Sin embargo, su eje central se concentraba en la lucha por la paz y la democracia, arraigado en un profundo engranaje nacionalista; actitud que le permitía tener relaciones políticas con diferentes sectores tanto de la guerrilla marxista como de personalidades de los partidos tradicionales.

Se vieron enfrentados al desencadenamiento de la violencia política en el país que enfatizó la inviabilidad de la lucha armada como medio para obtener las transformaciones políticas que necesitaba el país. Además, se abría paso una tendencia hacia la guerra civil que difícilmente podrían sostener las organizaciones populares. Ello hizo que, de una manera rápida, liderada por Carlos Pizarro León Gómez, se adelantaran negociaciones con el entonces presidente Virgilio Barco Vargas y que, a través de ellas pudieran desmovilizarse y entrar a la vida legal. Hecho que fue precedido de fallidos intentos para obtener la paz durante el gobierno de Betancur, pero que, sin embargo, recrearon en la cotidianidad nacional el interés por buscar alternativas a la guerra. ${ }^{7}$

La incorporación a la vida civil de la mayoría de sus miembros se produjo en un momento histórico en que difícilmente el conjunto de la sociedad podía aceptarlo como un signo de paz. De hecho, había sectores interesados en mantener la guerra; tanto desde posturas de derecha como en la extrema izquierda de las organizaciones guerrilleras. Fue así como su líder, Carlos Pi-

7 Un análisis minucioso del gobierno de Betancur y algunos de los problemas de los procesos de paz son analizados por Socorro Ramírez y Luis Alberto Restrepo, Actores en conflicto por la paz, CINEP, siglo XXI, Bogotá, 1988 
zarro León Gómez, fue asesinado a los pocos meses de reiniciar su acción civil, a través de una campaña electoral. Factor que no echó para atrás los acuerdos, a pesar de hacer difícil las acciones. Por ello, propiciaron la creación de una organización amplia en la que cupieran diferentes tendencias e ideologías que denominaron ALIANZA DEMOCRÁTICA M-19 (AD-M-19).

Fue esta organización la que participó en las elecciones para la Asamblea Nacional Constituyente, en 1990, y la que dentro de ella equilibró las fuerzas políticas que tradicionalmente habían estado bajo el control monopólico de los dos partidos tradicionales. Sin embargo, ese mismo hecho la enfrentó a permanentes negociaciones con diferentes sectores políticos y a participar en el gobierno sin una actitud independiente; lo cual deterioró su imagen hasta el punto de que, después de tener 22 congresistas, hoy sólo cuentan con una representante a la cámara. De todas maneras, su participación en esa asamblea fue factor decisivo para la incorporación en la constitución de aspectos sustanciales sobre Democracia participativa, autonomía regional, pluriculturalidad y Derechos Humanos.

\section{Otras Organizaciones de Izquierda}

El Partido Comunista Marxista-Leninista, surgió como alternativa política entre 1963 y 1964, a partir de la división que se dio en el campo internacional entre los partidos comunistas de China y Rusia, y sus repercusiones a nivel mundial, y su consecuente expresión en el Partido Comunista Colombiano, que incentivó contradicciones internas producidas desde su misma fundación en 1930. Se consolida también con algunas guerrillas liberales que funcionaban dispersamente. ${ }^{8} \mathrm{Su}$ objetivo estratégico era la revolución democrática popular que se fortalecía principalmente con campesinos, proletariado agrícola, indígenas y sectores medios de la población.

La confrontación que hacía al llamado "mamertismo" del PCC le permitió conquistar algunos espacios, especialmente en la costa norte en donde incluso creyeron tener una zona liberada. Negados totalmente a realizar una acción legal, privilegiaban la lucha guerrillera; por lo cual toda acción en sectores de masas estaba destinada a reclutar militantes para la guerrilla o dar apoyo logístico a ella.

En el proceso de paz adelantado en el gobierno de Belisario Betancur, aceptaron entrar en negociaciones, desarrollar algunas acciones de tipo legal

8 Véase Alejo Vargas Velázquez, "Guerrilla, régimen político y Estado: lecturas y relecturas" en Germán Palacio (comp.) La irrupción del paraestado. Ensayos sobre la crisis colombiana, ILSA-CEREC, Bogotá, 1990, p: 249-268. 
y conformar una organización paralela denominada Frente Popular. Este primer paso es continuado luego en el gobierno de Virgilio Barco y finalmente consolidado en el de Cesar Gaviria con su reintegro a la vida civil, a través de una organización política que denominaron Esperanza, Paz y Libertad (EPL). Sin embargo, un pequeño grupo se mantuvo en armas, continuando con la misma denominación y liderados por Francisco Caraballo, quien desde la cárcel pretende generar procesos de negociación.

El PRT y el QUINTIN LAME, fueron grupos pequeños de poca incidencia y cubrimiento del espacio político nacional. Sin embargo, este último tuvo un significado especial porque sus objetivos no se situaron en lo estratégico, como la mayoría de las anteriores, ni en perspectiva nacional. Surgió de la resistencia indígena contra asesinos a sueldo de los terratenientes, contra los grupos paramilitares y contra los grupos guerrilleros que operaban en su región, el departamento del Cauca. En cierta forma, también tuvo su justificación por las implicaciones que tuvo para las comunidades indígenas el enfrentamiento entre guerrillas y militares; máxime si se tiene en cuenta que la región en donde se ubicaban ha contado con la presencia de todos los grupos guerrilleros del país, es paso obligado de los comerciantes de la cocaína y productora de la mata de coca y de amapola.

Su lucha principal se estableció en función de la recuperación de la tierra y el mantenimiento de su cultura. Reivindicaron la propiedad sobre grandes extensiones de tierra, de las cuales tienen los correspondientes títulos de España, del siglo pasado. Defendieron su tradición cultural, impulsaron una educación bilingüe que les permitiera rescatar y consolidar su lengua. Exigieron el respeto a sus formas de organización social y política; especialmente los cabildos y sus formas de gobierno y las relaciones comunitarias que aún mantienen sus comunidades. Su reintegro a la vida civil con las comunidades se dio en el gobierno de César Gaviria como resultado de un proceso de negociación que les permitió obtener financiación de algunos proyectos económicos y culturales, compromiso con la defensa y respeto de lo más significativo de su tradición cultural, y tratamiento especial por medio de circunscripción nacional, para participar en el Congreso Nacional. Todo lo cual da cuenta de que antes de la irrupción del Ejército Zapatista de Liberación Nacional de México, hubo una organización guerrillera indígena en Colombia que postuló varios de los principios que hoy recorren el mundo como insignias del movimiento político mexicano y que fueron incluidos en la Constitución Política de Colombia. Sólo que ahora los cabildos y organizaciones indígenas del país adelantan movilizaciones en la búsqueda de garantizar que sus derechos no sean sólo formalidad jurídica sino posibilidad real para sus comunidades. 


\section{Procesos de Paz}

Desde la década de los 60's el curso de la violencia adquirió rumbos diferentes de los que había tenido anteriormente. Esta vez estaba marcada por los signos de descomposición de las instituciones, el auge de la lucha guerrillera y de las opciones de izquierda, el fortalecimiento del militarismo y de las formas autoritarias, el desbocado incremento de la pobreza y el agigantado peso del tráfico de drogas. Eso hizo que no se siguiera hablando de la violencia sino del entrecruzamiento de múltiples violencias. ${ }^{9}$ Sin embargo, las que han avivado la crisis política del país son las de la guerrilla y del narcotráfico. La primera fue tratada por el Estado de manera represiva hasta el gobierno de Belisario Betancur. La explicación de los gobernantes era que los objetivos de dichas organizaciones no iban más allá de reproducir en Colombia el experimento soviético; por tanto, las causas inmediatas y mediatas no se encontraban en el país sino en el comunismo internacional que pretendía acabar con los regímenes democráticos. Esto hacía que sus acciones simplemente se consideraran al margen de la ley y, por tanto, el deber del Estado era combatirlo para eliminarlo política, social y físicamente.

El trato dado al narcotráfico no fue igual. Hubo complicidad en muchos sectores del Estado con los grupos de narcotraficantes en ascenso. De hecho, no fueron pocas las campañas políticas financiadas por ellos ni escasos los miembros de la burocracia que recibieron sus dineros para agilizar o anular trámites. Hasta Pablo Escobar y Carlos Ledher llegaron a pertenecer a organismos parlamentarios, y en no pocos municipios del país se construyeron obras públicas con el dinero que ellos aportaban. Pero, esta luna de miel duró sólo hasta el momento en que su incidencia en la marcha del Estado y en la vida política del país fue tal que los mínimos controles eran insuficientes para detener sus desmedidas ansias de poder.

Fue así como se llegó a una situación límite en la que diferentes fuerzas políticas y sociales del país, y el mismo gobierno, no encontraron otra salida propicia diferente de impulsar procesos de paz o de darle tratamiento político y social a ambos problemas, y no simplemente represivo. De hecho, se producía en el gobierno y la sociedad civil, una tendencia generalizada a transformar las maneras como se habían enfrentado los problemas y a buscar otras formas de convivencia.

El sentido de la paz adquiría connotaciones especiales, dependiendo del punto de vista político desde donde se enunciara. La guerrilla concebía la paz sólo obtenible en la sociedad que estratégicamente se proponía 
alcanzar; argumento que pretendía justificar la violencia no como un fin en sí mismo, sino como el instrumento que dinamiza el ascenso hacia la Sociedad Socialista. El ejército la sustentaba en la búsqueda de asimilación de todas las formas de insurgencia y de generalización del delito al respeto y sumisión al Estado, asumido por ellos como de derecho, y al orden social que nos regía. Los partidos políticos tradicionales se identificaban, en gran parte, con lo anterior, pero jugaban a la ambigüedad de fortalecer la acción punitiva y de hacer demagogia sobre la apertura de espacios democráticos para generar nuevas formas de vida social.

Del narcotráfico no se puede establecer algo definido porque el carácter ilegal de su acción, la capacidad de enriquecimiento vertiginoso de sus protagonistas, la consolidación de monopolios internacionales, configurando un mercado transnacional, y su penetración a diferentes gobiernos e instituciones de Colombia y América Latina han hecho variar rápidamente su conducta en las acciones políticas y sociales del país. Los empresarios $\mathrm{a}^{10}$ rgumentaban que la paz sólo era posible en tanto se produjeran condiciones para la actividad productiva, mercantil y financiera; por eso auspiciaban una acción fuerte del Estado, especialmente en su función represiva, para detener la acción de la guerrilla y de la delincuencia común. Los gremios económicos así lo señalaban: "posibilidad de fortalecer y agilizar el funcionamiento de las tres ramas del poder público, con miras a generar un ambiente de estabilidad dentro del cual el proceso económico redunde en un mayor bienestar para todos los colombianos ...Pero una reforma institucional no alcanza su fin si el desorden continúa; si no se atiende el reclamo de seguridad de las gentes". ${ }^{11}$ Postura que tuvo una ligera variación con la investigación que el Congreso de la República le siguió al presidente Samper, al plantear que es necesario dar soluciones políticas a los conflictos que vive el país.

Es en esta intercepción de opciones que se presentó la propuesta de paz del gobierno de Belisario Betancur. Por primera vez se ubicaba, por parte de un presidente, el problema de la violencia en condiciones políticas y sociales. El hambre, la desnutrición y la miseria, fueron considerados terreno

9 El gobierno de Virgilio Barco nombró una comisión de académicos, en su mayoría, para que hiciera un diagnóstico sobre la violencia. El resultado fue el libro Colombia: Violencia y Democracia, Universidad Nacional de Colombia, Bogotá, 1987 En él se sacó el análisis de la violencia de la circunscripción que se hacía la confrontación de las guerrillas con el Estado y se identificaron aquéllas que tenían que ver con la delincuencia común, el narcotráfico, la familia, los medios de comunicación, los conflictos interétnicos, etc

10 El Espectador, febrero 28 de 1988, p: 12A. 
fértil para la delincuencia común y acicate para las opciones de izquierda que habían. De igual manera se consideró que la solución represiva de los conflictos no podía ser la política por excelencia de un gobierno; máxime que más de treinta años de hacerlo habían polarizado a las partes sin que ninguno pudiera declararse vencedor o vencido.

A esta formulación de principios le sucedieron acciones prácticas que dieron cauce al denominado proceso de paz. En especial, se conformó una Comisión Nacional de paz integrada por miembros de todos los partidos políticos, de la iglesia, expresidentes, empresarios y varias personalidades del país. A la postre, esta heterogeneidad y la gaseosa estrategia que se le definió la minó por dentro hasta llevarla a su descomposición. Porque no se podía luchar por la paz como un fin en sí mismo si no se partía de tener en cuenta el reconocimiento del sentido de la existencia de cada una de las partes.

A pesar de ello el compromiso con la paz se abrió camino en el país. Principalmente porque se produjeron diálogos directos con los insurrectos; en especial con las FARC, el EPL y el M19. Porque se convocó a los partidos políticos y a la sociedad a elaborar una reforma política. Porque se impulsaron mesas de trabajo en las cuales participaron diferentes sectores de la sociedad, debatiendo sobre problemas centrales de la vida política y social del país. Porque se logró un cese del fuego. Porque se abrió el espacio para que las F ARC y el PCC conformaran una organización de carácter amplio: la Unión Patriótica (UP). Porque los medios de comunicación familiarizaron a los guerrilleros en el país mostrando que tenían un propósito político y, a la vez, poniéndolos a ellos en mayor contacto con la sociedad civil. Porque se efectuó una mínima reforma constitucional que autorizó la elección popular de alcaldes y se decretó un estatuto legal de los partidos que abría puertas para una mayor participación de la oposición.

Sin embargo, este proyecto no fue avalado por el ejército ni por los partidos políticos ni por los empresarios. En la práctica, el presidente quedó solo en su acción, que, por sí, era limitada, y fue torpedeado por las instancias anteriormente anotadas. El ciclo se cerró cuando las voluntades contrarias se enfrentaron a la toma del Palacio de Justicia por parte del M 19. Quizá fue esa la mejor razón para que las partes no encontraran punto de conciliación. El Ejército creyó hallar allí la expresión del "totalitarismo" y del "vandalismo" revolucionario, con que justificó el "minigolpe” de estado, por medio del cual arrasó con hombres y bienes encontrados en esa edificación. Los partidos tradicionales y los empresarios convergieron en el cauce que los llevaba, ahora sí, a unirse al gobernante para someter a la guerrilla. Ésta encontró en 
los hechos la expresión del autoritarismo de estado y la falta de competencia del presidente para afrontar los retos que se había impuesto. ${ }^{12}$

Sin embargo, todos seguían hablando de paz a su manera. Ahora con mayor énfasis por la agresividad de las fuerzas encontradas: paramilitares (que surgieron durante este gobierno de manera organizada, bajo la denominación de Más Muerte a Secuestradores), guerrilla, ejército y narcotráfico.

Por eso el gobierno del ingeniero Virgilio Barco Vargas (1986- 1990) planteó la paz de una manera diferente. Afrontó, principalmente asuntos económicos y sociales a través de un plan que pretendía solucionar problemas graves de las zonas más afectadas por los conflictos. Ese proyecto se denominó Plan Nacional de Rehabilitación. Se ocupó de estimular y financiar proyectos de desarrollo comunitario, apertura de carreteras, terminación y edificación de escuelas, realización y dotación de puestos de salud, construcción de sitios deportivos y de recreación.

Paralelo a ello efectuó conversaciones con los grupos guerrilleros, con el supuesto básico de que hubieran demostraciones reales del deseo de paz. Eso se lograría si hubiera cese al fuego y si los grupos se concentraran en áreas definidas, respetadas tanto por la guerrilla como por el ejército. Sólo así se impulsarían conversaciones conducentes a tener en cuenta las propuestas políticas y sociales de los grupos guerrilleros y las condiciones concretas que garantizaran su desmovilización y reintegro a la vida civil. ${ }^{13}$

Efectivamente, eso fue lo que aconteció con el M-19, EPL, PRT y Quintín Lame. Cada uno, por su lado, se ubicó en sitios en donde tenían más hombres y realizaban más operaciones. Si bien es cierto que fueron discutidas propuestas que tenían que ver con el conjunto de la nación, también lo es que, en la concreción de los acuerdos, esta parte quedó a la voluntad de los gobernantes y de los congresistas. Un ejemplo fue el del proyecto de reforma constitucional presentado por el presidente Barco, abortado por la mayoría del Congreso, y lo fue también su propuesta de acudir al pueblo, a través de un plebiscito, para reformar la constitución. Sin embargo esto no fue óbice para que se le diera continuidad a las negociaciones, hasta llegar a la desmovilización del M-19. Organización que obtuvo una precaria garantía de financiación de proyectos económicos y educativos para quienes se reintegraban

11 Para mayor complementaci6n se puede consultar el libro de Socorro Ramírez y Luis Alberto Restrepo, ya citado

12 Aspectos centrales de la propuesta gubernamental y documentos sobre el proceso se encuentran en PRESIDENCIA DE LA REPÚBLICA, Hacia una nueva Colombia La política de reconciliación, normalización y rehabilitación Historia de un proceso Dos tomos, Bogotá, 1989 
a la vida civil, protección para garantizar la seguridad de sus vidas y elaboración de una formalización jurídica que le permitiera, a éste y a los grupos minoritarios, favorabilidades para participar en la lucha política legal.

Paralelo a este proceso el gobierno de Barco se vio enfrentado a una de las arremetidas más fuertes del terrorismo que haya tenido la historia nacional. Por un lado, el narcotráfico usó todo su poder económico y sus relaciones con miembros de los organismos de seguridad para financiar organizaciones paramilitares y escuelas de sicario s con el fin principal de diezmar las fuerzas de izquierda, eliminar y desestabilizar las instituciones que confrontaran su negocio y las personas que se ponían en su contra.

Fue así como asesinaron al Ministro de Justicia del gobierno de Betancur, Rodrigo Lara Bonilla, al Procurador General de la Nación del gobierno de Barco, Carlos Mauro Hoyos, a dos candidatos presidenciales de la UP, Jaime Pardo Leal y Bernardo Jarmillo Ossa; al candidato a la presidencia por el liberalismo y líder reformador, Luis Carlos Galán Sarmiento, y al máximo dirigente del M-19, recién reintegrado a la lucha política legal, Carlos Pizarro Leongomez. A esta lista se agregan más de dos mil militantes de la UP, entre los que se cuentan miembros de diferentes organismos parlamentarios del orden municipal, departamental y nacional, y la de muchos activistas populares, dirigentes sindicales e intelectuales progresistas del país. Esto no quiere decir que todo pueda ser adjudicable al narcotráfico, porque ha sido comprobada la participación de miembros de los diferentes organismos de seguridad en las masacres y asesinatos; sin embargo, si es significativa la relación que se dio entre ambas instancias para cometer los delitos. Por otro lado, la guerrilla, de manera persistente el ELN, generalizó la realización de acciones terroristas; en particular en las zonas petrolíferas y en no pocas estaciones eléctricas del país. Las FARC no se quedaron atrás; es más, se puede afirmar que fueron estimuladas por el otro grupo a compartir sus acciones, medio que los llevó a fortalecer la Coordinadora Guerrillera Simón Bolívar, a través de la cual se centralizaron las acciones guerrilleras.

El panorama que se dibujaba no dejaba ninguna esperanza de paz, diferente de aquélla que se trazó cuando en las elecciones para presidente de 1990 el pueblo respaldó la convocatoria a una Asamblea Nacional Constituyente. Decisión que fue respetada por el nuevo presidente, César Gaviria Trujillo, convocando a elecciones para ello. Situación que le daría un nuevo aire a los procesos de paz reforzada con el mantenimiento de las conversaciones con los grupos guerrilleros que había avanzados en las negociaciones con el anterior gobierno. En este aspecto se avanzó hasta obtener la desmovilización del EPL, PRT, y Quintín Lame. Estos tuvieron en cuenta las imprecisiones de 
los acuerdos con el M -19 y avanzaron en definir mejores condiciones, para la reinserción de los desmovilizados, por parte de las instituciones del Estado y coincidieron en articularse con el proceso de la Constituyente, para lo cual obtuvieron cuatro curules.

Quizá la historia política colombiana no había registrado mayor expresión de la sociedad civil que la efectuada en la Asamblea Nacional Constituyente. En primera instancia, se produjo en un momento de confrontación abierta por parte de la ciudadanía y diferentes organizaciones políticas y gremiales contra los malos manejos de las instituciones, los politiqueros, los corrupto s, los clientelistas. En segundo lugar, en circunstancias únicas respecto del deseo de paz. En tercera instancia, porque la composición que tuvo fue la expresión de la heterogeneidad de la nación: guerrilleros, indígenas, evangélicos, etc. En síntesis, porque, por primera vez, ninguno de los dos partidos tradicionales tuvo la hegemonía, ni tampoco se posibilitaron acuerdos que permitieran la imposición de su mayoría. Todo esto facilitó que los constituyentes no se contentaran con una reforma, tal como había rezado la convocatoria a elecciones, sino que se propusieran producir una nueva constitución. La nueva Carta Constitucional es el resultado de todos los esfuerzos y esperanzas por construir la paz. Es meramente formal porque no representa un cambio real en la cultura política; pero como tal es una "caja de herramientas", como se denomina un periódico de educación política ciudadana, disponible para cualquier artesano o constructor del nuevo país.

Sustenta la soberanía en el pueblo. Precisa las relaciones de las religiones con el Estado, sin privilegiar ninguna de ellas, como lo hacía la anterior constitución. Garantiza la plurietnicidad y su correspondiente polimorfidad cultural. Descentraliza el Estado, dándole importantes atribuciones a las regiones y a los municipios. f Incorpora, con especial énfasis los Derechos $\mathrm{Hu}-$ manos y fortalece 1," los organismos y funciones de quienes los deben hacer cumplir. Establece como obligatoria la elaboración de planes de desarrollo con plena participación de la sociedad civil, ordenando que " prevalezca en ellos lo concerniente al gasto social. Traza definiciones respecto de la política ecologista que debe implementar el Estado. Introduce principios básicos para una reforma de la justicia. Mantiene la elección popular de alcaldes y establece la de gobernador. Depura los procesos electorales y las incompatibilidades para ejercer cargos públicos. Intensifica las formas de fiscalización de la burocracia estatal. Se plantea, explícitamente, la realización de una Democracia Participativa en nuestro país.

Existen vacíos en varios aspectos, pero hay un consenso en que puede ser una de las mayores contribuciones a la paz, siempre y cuando las tendencias 
que propician su búsqueda se fortalezcan y propendan por una cultura política favorable a la Democracia. Y siempre y cuando también que las fuerzas contrarreformistas no se impongan como parece podrá serlo con los proyectos de reforma que se discuten en el congreso, finalizando este año de 1996.

No sólo con eso sino también con la búsqueda del debilitamiento del militarismo estatal que cada vez adquiere más fuerza y la transformación del militarismo guerrillero en acciones políticas que contribuyan a que haya esperanza de que se puede construir una sociedad mejor que la que tenemos. 